\title{
Los capuchinos hispanos y sus misiones americanas durante la primera mitad del siglo XVII
}

\author{
The Hispanic Capuchins and their American Missions \\ during the First Half of the $17^{\text {th }}$ Century
}

DOI: https://doi.org/I0.22380/20274688.2057

Recibido: 30 de junio del 2021

Aprobado: 5 de septiembre del 2021
ANEL HERNÁNDEZ SOTELO*

Escuela Nacional de Antropología e Historia Tutivillus. Espacio de Agitación Histórica lunadearado@hotmail.com

\section{R E S U M E N}

La llegada de los frailes capuchinos a América estuvo precedida por sus experiencias misionales en el Congo a mediados del siglo xvir. Desde el punto de vista apostólico, fue también la primera experiencia de misión frente a infieles, ya que la ofMcap hasta entonces se había dedicado a la conversión de herejes en Europa. Historias cruzadas entrelazan estos hechos con la primera misión de capuchinos al Darién y, posteriormente a Cumaná. De las plumas de fray Juan de Oviedo y de José Carabantes, nos enteramos de cómo fue el desarrollo de ambas misiones transatlánticas.

Palabras clave: capuchinos, misiones, el Darién, Cumaná, siglo XVII

\footnotetext{
Doctora y maestra en Humanidades con especialidad en Historia Moderna de la Universidad Carlos III de Madrid, España; licenciada en Historia de la Escuela Nacional de Antropología e Historia (eNAH), Ciudad de México, México; investigadora en estancia posdoctoral en el Centro de Estudios de las Tradiciones de El Colegio de Michoacán, México; certificada en Teoría Crítica por el Instituto de Estudios Críticos 17, Ciudad de México, México; miembro del Sistema Nacional de Investigadores de México (nivel I), desde el 2013 a la fecha; galardonada con la Mención Honorífica en el Premio Edmundo O’Gorman (Teoría de la Historia e Historiografía) del Instituto Nacional de Antropología e Historia de México en el 2005 y Mención Honorífica cum laude en la obtención del grado de doctorado en el 20 I. Autora del libro Una historia de barbas y capuchas. La deconstrucción de la figura de san Francisco por los frailes capuchinos. Siglos XVII-XVIII, publicado por el Instituto Colombiano de Antropología e Historia en el 2017.
} 


\section{$\begin{array}{llllllll}\mathbf{A} & \mathbf{B} & \mathbf{S} & \mathbf{T} & \mathbf{R} & \mathbf{A} & \mathbf{C} & \mathbf{T}\end{array}$}

The arrival of the Capuchin friars in America was preceded over by their missionary experiences in the Congo in the mid-1 $17^{\text {th }}$ century. From the apostolic point of view, it was also the first experience of mission in front of infidels, since the ofMcap until then had dedicated itself to the conver- sion of heretics in Europe. Cross stories intertwine these events with the first mission of the Capuchins to Darien and, later, to Cumaná. From the pens of Fray Juan de Oviedo and José Carabantes, we learn about the development of both transatlantic missions.

Keywords: Capuchins, missions, El Darién, Cumaná, $17^{\text {th }}$ century

\section{El preludio africano}

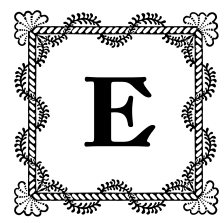

1 siglo Xvir fue el siglo de la consolidación de la Orden de Frailes Menores Capuchinos (en adelante, ofmcap) en la península ibérica. Los religiosos iniciaron la centuria expandiéndose hacia Navarra, Andalucía y Castilla entre I606 y i613, lo que determinó la ampliación de la jurisdicción capuchina hispana y su división en seis provincias: Madre de Dios de Cataluña, Inmaculada Concepción de $\mathrm{Na}$ varra-Cantabria, Preciosísima Sangre de Cristo de Valencia, Virgen del Pilar de Aragón, Encarnación de las dos Castillas e Inmaculada Concepción de Andalucía (Echeverría). Además, en I6rg se suprimió la dependencia de los capuchinos al ministro general de los conventuales, con lo que la ofmcap se convirtió en una rama autónoma del franciscanismo observante y del conventual (Hernández).

Desde el siglo Xvi los capuchinos habían hecho su trabajo apostólico entre los "herejes" protestantes en los territorios actuales de Italia, Austria, Suiza, Alemania y Francia ${ }^{1}$. En las primeras décadas del siglo XviI, los frailes solicitaron a la Congregación de Propaganda Fide las licencias para misionar en Japón, China y Filipinas. Sin embargo, la Congregación se negó considerando que, comparativamente, en el continente africano era escasísimo el número de misioneros. Y fue así como comenzó el ejercicio de las misiones exteriores capuchinas: la misión del Congo fue 
la primera misión entre infieles que oficialmente tuvieron los Capuchinos espańoles, aunque no estuviese encomendada a ninguna Provincia, ni tampoco a solos los españoles, ya que conjuntamente misionaron allí también italianos y éstos fueron los que en definitiva quedaron encargados de dicha misión. (Carrocera, La Provincia i84)

Luego de los frustrados intentos de diferentes órdenes religiosas para establecer una misión en el Congo desde finales del siglo $\mathrm{XV}^{2}$, en I6I8 el pontífice Pablo V resolvió enviar misioneros capuchinos a la región a petición de Álvaro III, rey del Congo, pero la iniciativa careció de éxito como en las ocasiones anteriores. No obstante, sirvió para que en 1643 el padre Inocencio de Caltagirone (ministro general de la ofMCap entre 1643 y 1650) designara a un grupo de religiosos para realizar una nueva expedición misionera al Congo. El grupo estuvo compuesto por cinco italianos, además de Francisco de Pamplona "que tenía ya autorización de la Sda. Congregación desde 1642" y Miguel de Sessa, "napolitano de nacimiento, aunque agregado a la Provincia de Aragón, que también tenía permiso desde i643”. A ellos se sumarían más tarde otros cinco capuchinos hispanos que hicieron su solicitud en 1644 y todos se embarcaron rumbo al Congo el 20 de enero de i645. En i646 zarpó una nueva expedición al Congo, compuesta por cuatro capuchinos italianos que no llegaron a su destino "por haber sido detenidos por los protestantes y obligados a regresar a Europa”, pero al mismo tiempo los prelados capuchinos de Castilla escribieron a Propaganda Fide para enviar trece nuevos misioneros; sin embargo, "la Congregación no quería confiar dicha misión a los Capuchinos españoles". A pesar de las dificultades, Inocencio de Caltagirone siguió promoviendo la misión del Congo y en 1647 salieron desde Cádiz rumbo a la costa africana catorce misioneros capuchinos: ocho italianos y seis españoles, siendo estos los últimos hispanos que viajaron al Congo, pues a partir de 1658 la misión quedó al mando exclusivo de los capuchinos italianos. La suerte de los capuchinos

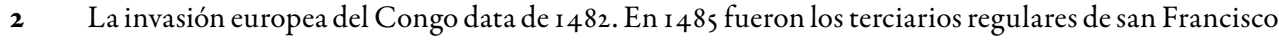
quienes se encargaron de las tareas de evangelización. Más tarde, entre I 490 y I 49I, a la empresa se sumaron dominicos, franciscanos y miembros de la Congregación de Canónigos de San Juan Evangelista, "disputándose unos y otros la gloria de haber sido los primeros". Hacia 1582 fueron los jesuitas y los carmelitas descalzos quienes intentaron establecer nuevamente la misión, pero "como dicho apostolado resultaba harto duro y martirizador, casi todos los mencionados religiosos se fueron retirando" (Carrocera, La Provincia $184-185)$. 
hispanos en el Congo fue mortal pues solamente regresó a España el padre Juan de Santiago, con graves enfermedades (Carrocera, La Provincia I85-186).

A pesar del accidentando desarrollo de esta misión, los capuchinos hicieron algunos adelantos. Se sabe que el padre Buenaventura de Cerdeña organizaba las escuelas para niños y jóvenes, y que compuso una gramática en lengua castellana y congolesa, con lo que fue él quien enseńó la lengua originaria a los capuchinos españoles que zarparon rumbo al Congo en i647. Además, "juntamente con el sacerdote mestizo, Manuel Reboredo” — después Francisco de San Salvador como capuchino- compuso el primer diccionario trilingüe latino, castellano y congolés. Del religioso Juan de Santiago sabemos que misionó entre I646 y I648 y que sufrió constantes enfermedades. A su vuelta a España en I649, fue vicario y maestro de novicios en el convento de Toro (1652-1655), para luego mudarse al convento de Toledo donde murió. De Santiago presumía de que durante su actividad misionera en el Congo se había encargado de la instrucción lectoescritural y espiritual de hasta 580 indígenas, que había bautizado a 9000 niños y convertido a "herejes" holandeses, además de haber celebrado mil matrimonios entre personas piadosas que le servían de intérpretes (Carrocera, $\mathrm{La}$ Provincia I87-I89)3. Incluso se tiene noticia de que José de Pernambuco, natural de Brasil pero perteneciente a la Provincia de Castilla, egresado de Salamanca, capuchino desde 1634 y enviado a la misión congolesa en I647, "predicaba sin intérprete 'por hablar la lengua del Congo'”. Pernambuco y otro capuchino castellano, Francisco de Veas, predicaban contra las "supersticiones" del pueblo nativo y mientras uno alzaba la voz en la plaza, el otro entraba "por las casas recogiendo todos los idolillos" para, finalmente, formar una hoguera pública con lo recogido (Carrocera, La Provincia 190).

Paralelamente al desarrollo de la Misión del Congo, los capuchinos de la Provincia de Andalucía solicitaron a Propaganda Fide el permiso para participar en la Misión de Guinea y Sierra Leona, que les fue concedido en I644. En I646, catorce capuchinos andaluces y dos capuchinos castellanos se embarcaron en Sanlúcar de Barrameda para llegar al puerto de Alé. Ahí se quedaron cuatro misioneros y el resto viajó rumbo al puerto de Gambia. Tres misioneros se internaron en la zona, pero los expedicionarios portugueses los

3 Dejó en manuscrito tratados espirituales, una relación de su viaje al Congo y algunos rudimentos pedagógicos en lengua congolesa. Por referencia indirecta de Carrocera (Carrocera, La Provincia 190) sabemos que fue autor de una obra impresa: Recuerdo de dormidos. Refugio de atribulados. Socorro de Agonizantes. Madrid: Melchor Sánchez, 1672, de la que no he tenido noticia. 
calificaron como espías y fueron apresados y enviados a Lisboa. El resto sufrió fuertes enfermedades y poco logró hacer, por lo que "acordaron dejar aquellas tierras africanas y dirigirse al Marañón o Amazonas, pues para ello tenían ya permiso de la Congregación" (Carrocera, La Provincia 192)4. Al parecer, fueron solamente dos capuchinos los que se negaron a abandonar la Misión de Guinea y Sierra Leona: los castellanos Antonio de Jimena y Serafín de León, quienes se dedicaron a predicar la doctrina cristiana y a bautizar gentiles hasta que murieron sexagenarios en 1655 y I657, respectivamente 5 . Estas fueron las primeras experiencias misioneras entre "infieles" del exterior que sirvieron a los capuchinos hispanos como preludio de las actividades que realizarían en sus expediciones americanas.

\section{La Misión del Darién}

Los capuchinos hispanos misionaron por primera vez en América en el Darién, que comprendía una extensa región de la costa atlántica, desde el río Sinú, en Colombia, hasta el río Mandinga en Panamá. En su centro se encontraba el golfo de Urabá en el que desaguan más de treinta ríos. El principal es el río Atrato, uno de los más caudalosos del mundo con relación a la longitud de su curso, 750 kilómetros. (Pacheco 289)

En la región eran distinguibles dos zonas: "el Darién del Norte, al oriente del golfo de Urabá, y el Darién del Sur en el Istmo de Panamá, con costas a ambos océanos" (Pacheco 289).

A finales de 1646, fray Francisco de Pamplona, quien se había embarcado hacia el Congo un año antes, se encontraba en Roma informando a los miembros de Propaganda Fide sobre los avances en África. La Congregación

4 La Congregación de Propaganda Fide confió la Misión de Amazonas y Marañón a los capuchinos valencianos. Sin embargo, el Consejo de Indias denegó a los religiosos las licencias para pasar a América, argumentando que en la región ya misionaban franciscanos observantes y jesuitas (Pobladura).

5 La Misión de Guinea y Sierra Leona fue restablecida por los capuchinos castellanos en 1677 y terminó en 1688. Sobre esta segunda expedición apuntó Carrocera que en Sierra Leona "había muchos ingleses, enemigos de los católicos, y asimismo gran número de portugueses, dedicados al tráfico de esclavos", además de que hacia 1683 se unieron a la misión frailes franciscanos (Carrocera, La Provincia 223-229), con los que los capuchinos tuvieron no pocos problemas dada su histórica rivalidad por demostrar quiénes eran los verdaderos herederos de san Francisco (Hernández). 
comisionó al religioso para comunicar a los capuchinos un nuevo encargo: la fundación de la Misión del Darién. Sin embargo, el impedimento de los capuchinos para pasar a América estaba en el Consejo de Indias, institución que, desde su fundación en I5II,

tenía para América atribuciones excepcionales, hasta el punto de ejercer la suprema jurisdicción de todos los territorios españoles en la Indias Occidentales, tanto en el orden gubernativo como en el judicial y legislativo, pudiendo hacer para ellas leyes, ordenanzas, pragmáticas, así generales como particulares. (Carrocera, "El Consejo" 28I)

Así, desde el siglo xvi los consejeros indianos decidieron cuáles eran las órdenes religiosas más idóneas para viajar a América, erigir conventos y realizar el apostolado misional. Las órdenes favorecidas fueron los franciscanos, los dominicos, los agustinos, los mercedarios y, más tarde, los jesuitas. Además, aunque la ofmcap quedó canónicamente erigida por Clemente VII en I528, los prejuicios de Carlos V y de Felipe II sobre los frailes capuchinos — a quienes consideraban miembros de una "secta"- impidieron su establecimiento en la Península. No fue sino hasta 1578 cuando lograron su primera fundación hispana en la capilla de Santa Eulalia de Sarriá, en Barcelona (Hernández).

El Consejo de Indias consideró que la introducción de los capuchinos al Darién generaría problemas porque ya existían ahí otras órdenes religiosas, lo que "podía dar lugar a disgustos entre unos y otros, y que, aun cuando dicen [los capuchinos] que no fundarán conventos, la necesidad les obligaría o estarían en casas particulares y no conviene". Además, en un decreto firmado en diciembre de 1646 , los consejeros ordenaron a todos los religiosos radicados en América que no tuviesen convento, regresar a España. Y un obstáculo más para que los capuchinos lograran las licencia para pasar al Darién era que el Consejo de Indias alegó "que las misiones debían ser organizadas por el Consejo y no por la Congregación de Propaganda Fide" (Carrocera, "El Consejo" 282, 286). No obstante, en agosto de 1646 un grupo de capuchinos había escrito al provincial y al definitorio de Castilla solicitando que "se sirvan y dignen de escribir a la Sacra Congregación. Pidiéndola conceda a esta Provincia, despachos para que salga misión de ella para el Congo [...] o para otras tierras de infieles que tengan dependencia del rey de España" (Pena IoO4).

Frente a las impugnaciones del Consejo y al celo misionero de los capuchinos castellanos, en 1647 fray Francisco de Pamplona se entrevistó con Felipe IV, con quien tenía algún lazo de amistad pues el religioso antes de tomar el hábito 
había sido maestro de campo y general de la Armada española. Pamplona logró obtener una cédula real en la que se le autorizaba, junto con otros cuatro o cinco capuchinos castellanos, el paso al continente americano, aun a pesar de las controversias que suscitó el asunto en el Consejo de Indias (Carrocera, "El Consejo"; Carrocera, La Provincia I94-197).

El viaje de los religiosos a América no fue nada fácil. Los capuchinos castellanos se embarcaron en Cádiz el 17 de octubre de 1647 y llegaron a Cartagena de Indias el 6 de diciembre del mismo año. De allí hicieron un camino de cincuenta horas hasta Portobelo, para luego llegar a Panamá por el río Chagre el is de enero de 1648. En Panamá tuvieron una estadía de tres meses, debido a que todos enfermaron durante la travesía. Recuperados, el 28 de abril tomaron rumbo al Darién, y llegaron al puerto el 3 de mayo de 1648 (Pena I007). Este grupo de castellanos estuvo encabezado por el prefecto de la Misión del Darién, fray Antonio de Oviedo, al que se le sumaron misioneros capuchinos andaluces dirigidos por fray Gaspar de Sevilla, quien "había venido a América en busca de un campo misional, ya que no había podido entrar en Guinea” (Pacheco 293).

Los capuchinos andaluces se establecieron en Urabá y fundaron el pueblo de Tunacuna, pero "bien pronto recibieron orden de sus superiores de regresar a España, por haber muerto numerosos religiosos en la provincia”. Los capuchinos castellanos tomaron rumbo a Panamá y luego por el río Tarena. Sin embargo, entre I651 y 1652 el padre Oviedo fue asesinado por los bugatas ${ }^{6}$, y el resto de los misioneros decidió entonces regresar a España, terminando así la empresa (Pacheco 294).

Fray Antonio de Oviedo murió misionando al internarse en la tierra de los bugatas con dos indígenas y dos soldados. De acuerdo con el cronista Mateo de Anguiano, Oviedo "prosiguió su navegación, y queriendo pasar a explorar los ánimos de los bugatas, le dejaron los que le acompañaban; y desde la entrada del río, que va a esta nación, se volvieron. Echáronle en tierra, y fue río arriba; pero brevemente cayó en manos de unos indios gorgonas a quienes predicó, y ellos le quitaron la vida a saetazos y lanzadas; y no contentos con haberle dado muerte tan cruel, le serraron el caso de la cabeza, e hicieron taza de él para beber. La sangre del venerable padre, fue la primera de capuchinos que los fieles vertieron en nuestras Indias, cuya muerte sucedió cerca del día 17 de septiembre de 1652" (Pena IOI2). A reserva de una profunda investigación, Carrocera apuntó que "aunque el P. Anguiano dice que el martirio del P. Oviedo tuvo lugar en 1652 , creemos ser más verídico haya tenido lugar en 1651, por los hechos que sucedieron posteriormente" (Carrocera, La Provincia 196), mientras que Smutko escribe que "los indígenas atravesaron al P. Antonio con lanzas y flechas y, finalmente, hicieron del casco de su cabeza una taza para beber [en] el mes de septiembre, el año del Señor I65I" (Carrocera, "Los capuchinos" io9). 
Gracias a las cartas remitidas por fray Antonio de Oviedo como prefecto de la Misión del Darién al provincial de Castilla, como también a la transcripción de ellas realizada por Peña González, se conocen algunas noticias sobre el desarrollo de esta misión. Se sabe que algunos de los capuchinos que habían participado en la Misión del Congo decidieron embarcarse hacia la empresa del Darién, como Francisco de Pamplona; otros, como José de Pernambuco (que se ocupaba de hacer las hogueras con los "idolillos" congoleses), ganaron tan buena fama en África que el prefecto Antonio de Oviedo quiso hacerlos sus compañeros en América, aunque sin éxito (Pena Ioı).

Oviedo refiere que en Sanlúcar de Barrameda (donde estuvieron forzadamente por el mal clima) fueron recibidos "con poco gusto" por otros capuchinos legos que se dirigían al Congo y que algunos de ellos le suplicaron que los llevara consigo rumbo a América porque la empresa africana estaba muy detenida. Asimismo, señala que al Darién se dirigían frailes que le inspiraban desprecio, por su conocida desobediencia, discordia y holgazanería, como era el caso del lego "fray Francisco" que había ganado fama como el saboteador de la Misión del Congo (Pena ior3).

Si bien se ha dicho que la Misión del Congo supuso un preludio para el apostolado americano, también es verdad que la variedad lingüística y cultural de los pueblos del Caribe y del Circuncaribe, su organización tribal seminómada, las limitaciones que suponían para los frailes la topografía y el clima del lugar, y el talante guerrero de sus habitantes marcaron profundas diferencias entre ambas misiones (Helms), como se corrobora al leer la descripción que hace Oviedo sobre el modo de transporte y la tremenda necesidad que tenían los europeos de los indígenas para tal efecto:

Llegamos al primer puerto del Darién, el día de la cruz de mayo, a donde estuvimos diez días aguardando canoas, que son unos artesones de un palo, para subir al primer lugar a donde llegamos en tres días, llámase este pueblo San Enrique, habitación y doctrina de los padres dominicos. [...] Allí estuvimos casi un mes, mientras don Julián dispuso el camino habiéndole ya los indios para que llevasen el hato, tardamos ocho días en llegar al sitio donde estamos. Cuales son los caminos, sólo digo que fue patente mi logro el no despeñarnos. El padre Lorenzo caminó en hombros de indios en una hamaca. Llegamos a este sitio víspera de San Antonio de Padua, aunque yo rendido de las cuestas llegué dos días después, porque me quedé en casa de un indio. (Pena I024) 
Sobre los nativos, el prefecto insistía en que uno de los problemas de la misión era que "viven estos indios apartados unos de otros en sus estancias, cada uno es señor en su casa, es gente bárbara y que primero es necesario enseñarles a ser hombres que cristianos". Para Oviedo, los naturales del Darién no eran hombres porque "no tienen ídolos ni adoración”, razón por la que era urgente la construcción de iglesias "de palos y ramas, según el uso de la tierra, que aquí no hay otros edificios" 7 . De tales circunstancias resultaba en extremo difícil reducirlos en pueblos porque

el irlos a buscar a sus casas es cosa imposible porque ni hay camino, ni para los caminos que hay, y ellos como he dicho están muy divididos unos de otros, a las orillas de los ríos que son muchos y rápidos, sin puentes y malos vados. (Pena I024, I025, I027)

Con respecto a las costumbres de los naturales, el prefecto señalaba que los hombres andaban totalmente desnudos, mientras que las mujeres solían cubrirse de la cintura para abajo, con excepción "de las de la Gorgona, que es otra provincia que toca a ésta, [que] están totalmente desnudas”. Le sorprendía que "no aran ni cultivan la tierra, sólo para sembrar maíz, plátanos, yucas y otras semillas cortan el monte y le siembran sin más beneficio y no sirve esto más de para una siembra", además de que "las cabalgaduras no las conocen ni las hay, ni hay otros animales domésticos que perros que les sirven para sus cazas, que es la carne que comen. Gallinas crían, pero aún nos [sic: no] las comen mucho”. Sobre los bienes apreciados por los indígenas, Oviedo escribió:

su ajuar [...] es una hamaca de algodón o hierba para dormir, arco y flechas y lanza, y unas ollas que hacen las mujeres para cocinar, y cuentas de abalorio son su tesoro. No estiman oro ni plata, sólo unas pasenas [sic] que traen en las narices los hombres, y un arquillo de hilo de plata o oro con que se engalanan. (Pena ro29)

Otra de las costumbres que llamó la atención del misionero fue "que cuando las mujeres llegan ya a ser para casarse, las encierran en una jaula hecha de

7 A pesar de la visión del capuchino sobre la espiritualidad de los nativos, según otras fuentes, los indios cunas del Darién "admitían la existencia de un Dios supremo, quien vivía en su casa de oro y plata, adornada de espejos, sentado en un banquito de oro. Este Dios estaba del todo ignorante de lo que pasaba en el mundo, y los únicos informes que recibía eran los de los indios que morían e iban al cielo. Era distinto del Dios de los blancos" (Pacheco 290 ss.). 
cañas y muy obscura, de suerte que sólo tienen una ventanilla, y allí las tienen un año encerradas hasta casarlas". Finalmente, aunque todos los grupos tribales eran belicosos, los indígenas de la Gorgona y de Urabá "no comen carne humana como los maritueses" (Pena I024, I029).

La correspondencia de fray Antonio de Oviedo revela la tensión que hubo entre capuchinos y dominicos en la Misión del Darién. Los dominicos conocían la zona desde el siglo XVI, pues acompañaron a soldados y expedicionarios en sus campañas por la región. Según se desprende del epistolario de Oviedo, en I648 los dominicos cumplían doce años de misión en el Darién, razón por la que a uno de ellos "no le hizo buen estómago [la presencia de los capuchinos] y habló algo más diciendo, que veníamos con nuestras manos atadas a llevar la gloria de lo que ellos tenían trabajado, y que el Darién estaba convertido". $\mathrm{Y}$ es que "los padres dominicos sintieron mucho nuestra misión. Hicieron sus diligencias para estorbarla, porque tienen tres religiosos en el Darién y véseles interés", ya que acostumbraban "a tratar, comprar y vender" con los naturales. En suma, el capuchino escribió que "gasta el Rey su dinero y sin provecho, porque no parece que hay noticia de Dios, aunque hay muchos bautizados piden los pobres quien los doctrine, y no hay quien lo haga" (Pena I019, I022, I030, I038).

Según Oviedo, los padres dominicos habían bautizado a muchos infieles "que no saben cosa alguna de lo que deben saber", razón por la que hacia I649 el prefecto había dado el bautismo solamente a 46 niños y a ningún adulto “porque hasta que estén bien instruidos no es justo". De ahí que el capuchino prefiriera dedicarse a hacer un "catecismo en preguntas y respuestas en su lengua, ayudado del intérprete, y otro hice magistral". Estas iniciativas, sin embargo, resultaban insuficientes pues en mayo de 1650 el prefecto refirió que, pese a los esfuerzos por adoctrinar a los nativos, estos continuaban diciendo disparates como "que el topo había hecho la tierra y que es señor de ella", y haciendo sacrificios al diablo con borracheras, bailes y música, "quemando cacao y bebiendo su humo, y de este cacao usan los mojanes, y de tabaco para las curas de los enfermos, invocando al demonio" (Pena I029, I030, I038, I042, I043). Incluso, en medio de la prédica, los naturales amenazaban al religioso, pues

como les traté de la muerte, no pudiendo sufrirlo me amenazaron que si alguno de ellos se moría, que luego me habían de alancear. Y sucedió que al que me amenazó se le murió su madre dentro de pocos días y se la llevaron los diablos, por lo cual ni ha venido más a rezar ni me ha visto más. No se [sic: sé] en que parará, porque ellos son traidores. Otro 
cuya mujer es mojan, tuvo la lanza que era de palma silvestre y muy dura, tostada ya en el fuego para matarme. (Pena I043)

Al iniciar la década de I650, viajó a la región un destacamento de soldados para proteger a los misioneros y, con seguridad, para reducir por la fuerza a los nativos. Estos se tornaron más violentos al ver que "se puso en el Darién una guarnición española, lo cual, en vez de calmar los ánimos, los excitó más, en la creencia de que iban a atacarlos", por lo que respondieron recluyendo "al padre Francisco de Canarias en una isla solitaria para que muriese de hambre", apresando y maltratando al padre Basilio de Valdenuño (Carrocera, La Provincia 196) y, finalmente, asesinando al prefecto Antonio de Oviedo. Y es que, la persecución que sufrieron los capuchinos "no fue por odio contra la fe, sino por ser identificados con los soldados españoles de la guarnición” (Smutko Io9).

Fue así como la Misión del Darién terminó para los capuchinos, aunque intentaron recuperarla años más tarde debido a que en 1654 "la Congregación para la Propagación de la Fe extendió el territorio del Darién a las regiones circunvecinas" y "exhortaba [al Provincial capuchino de Castilla] a proseguirla y a que se enviasen más misioneros" (Carrocera, La Provincia 197). De ahí que en I658 se comisionara al padre Miguel de Madrid para buscar en España nuevas vocaciones para el Darién, pero la empresa fue un fracaso. Según Smutko, "La primera etapa de la historia de los capuchinos en el Darién terminó definitivamente en 1659. Luego fray Miguel de Madrid pasó a la misión de Cumaná donde recibió la palma del martirio" (Smutko iıo) ${ }^{8}$.

8 La Misión del Darién tuvo una segunda etapa. Entre 168I y 1689 los capuchinos castellanos se encargaron nuevamente de su organización. Sabemos que en 1681 salió una misión de siete capuchinos castellanos rumbo al Darién, dirigidos por el padre fray Bernardino de Madrid, y que los religiosos pudieron fundar "dos poblaciones, una en el río Terena, y otra en las riberas del río Paya. Pero la rebelión de los indios los obligó a regresar a Panamá y luego a España en I689" (Pacheco 294). Y es que "surgieron las mismas dificultades que terminaron con la primera misión en el Darién. Los antiguos enemigos de los españoles, los piratas ingleses, holandeses y franceses, incitaron a los indígenas contra el gobierno. Ellos se levantaron contra los españoles, dando muerte a muchos. Entonces, el Gobernador, mirando el grave riesgo de vida que presentaron tanto para los piratas como para los indígenas, ordenó a los capuchinos retirarse de Panamá” (Smutko II2). Sobre los conflictos con "los enemigos de los españoles", en 1647 fray Antonio de Oviedo solicitaba al provincial de Castilla que "me envíe las controversias de Becano, que es un tomo crecido, porque andan por estas costas ingleses” (Pena I02 I). Probablemente, se refería al Tractatio dilucida et compendiaria omniun fide controversiarum. Lugduni: Antonii Pillehotte \& Ioan Caffin, 1624, del jesuita Martino Becano. 


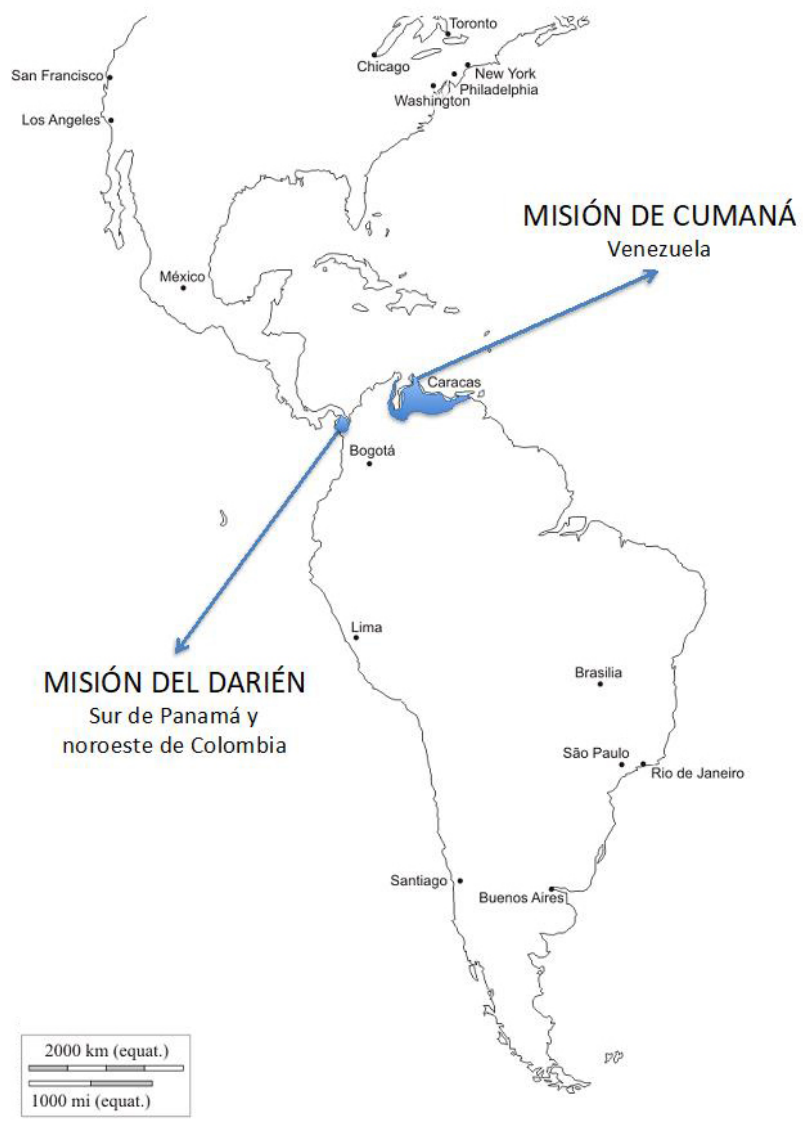

$\rightarrow$ FIGURA I.

Misiones de capuchinos hispanos en América, primera mitad del siglo XVII Fuente: elaboración propia.

\section{La Misión de Cumaná}

Pese a su trágico desenlace, la Misión del Darién fue importantísima para la ofmcap pues permitió a los religiosos pisar tierras americanas, aunque con la salvedad impuesta por el Consejo de Indias de estarles prohibida la erección de conventos en el continente. En I650 Francisco de Pamplona - el mismo fraile que había conseguido tres años antes la cédula real para el embarco hacia el Darién- obtuvo un "permiso para embarcarse, acompańado de otros tres religiosos, rumbo a la isla de Granada, con el fin de dedicarse en ella a 
la evangelización de sus habitantes" (Abaurre 83)․ Sin embargo, los franceses ocupaban la isla y no se les permitió el desembarque, por lo que los religiosos se dirigieron a "la provincia de los Cumanagotos, donde por un ańo vivieron por entero consagrados a la reducción y conversión de los múltiples indios que en ella había" (Carrocera, Lingüistica II). Fue así como arribaron por primera vez a la Misión de Cumaná, la cual

comprendía la antigua provincia del mismo nombre, llamada también Nueva Andalucía, y sus límites, en líneas generales, fueron: partiendo del Golfo Triste hasta la ciudad de Cumaná, y luego la misión de Píritu hasta el Orinoco, más las bocas de este río, o sea, todo el delta. (Carrocera, Misión XV)

Pese al providencial arribo y a la larga estadía en Cumaná, los religiosos tuvieron que esperar varios años para establecerse formalmente pues "eran necesarios más misioneros y, sobre todo, contar con la autorización así de Propagada Fide como del Consejo de Indias”. En r65r Francisco de Pamplona salió rumbo a Espańa para conseguir tales licencias, pero

al llegar al puerto de La Guaira le sorprendió la muerte el 20 de agosto [...] y, como remate, una cédula del 3I de diciembre de I65I ordenaba a sus dos compañeros, PP. Lorenzo de Magallón y Antonio de Monegrillo, dejar aquellas tierras y regresar a la patria. (Carrocera, Lingüistica II)

Vueltos a España, Magallón y Monegrillo enfrentaron sendos pleitos en el Consejo de Indias: primero, por obtener los permisos de los consejeros para regresar a Cumaná y, después, para litigar contra los franciscanos su derecho a misionar en aquellas tierras. Finalmente, en I654 el Consejo de Indias determinó que la "conversión de los indios cumanagotos" se encargara a los franciscanos y no a los capuchinos. Sin embargo, el capuchino Lorenzo de Magallón continuó el litigio en el Consejo de Indias y, gracias al apoyo de la nobleza madrileña, logró que en 1657 Felipe IV expidiera una cédula real en la que se le autorizaba, junto con cinco compañeros, a regresar a Cumaná. Dicha cédula se acompañaba de otra para el gobernador de Cumaná, Pedro de Brizuela, "ordenándole señalase a los Capuchinos sitio conveniente para misionar" (Carrocera, Lingüística II; Carrocera, Misión 15-25). 
Así, en 1658 fueron los religiosos aragoneses los que se establecieron formalmente en la Misión de Cumaná. Les siguieron la Misión de los Llanos de Caracas, instaurada por los capuchinos andaluces a mediados de 1658 , siendo la misión capuchina más extensa pues limitaba con "la misión de Píritu [...] desde el río Pariaguán hasta Barquisimeto, y desde San Felipe y Altagracia hasta el río Apure [hasta] la ribera izquierda del Meta"; las misiones de Trinidad y de Guayana, que comenzaron los frailes catalanes en 1678 y 1682 , respectivamente; y la Misión de Maracaibo, que "estuvo unida a la de Santa Marta y dio comienzo en I693, siendo encargada a los Capuchinos valencianos" (Carrocera, Misión XVI) ${ }^{\text {10 }}$.

Es evidente que las condiciones en las cuales los capuchinos llegaron a tierras venezolanas resultaron propicias para esta rápida expansión. En principio, la región ya contaba con un gobernador, es decir, había sido pacificada, a diferencia de lo que sucedía en el Darién donde la reducción de los indígenas parecía imposible. Se sabe que hacia 1650, cuando los primeros capuchinos pisaron Tierra Firme, existían al menos tres ciudades de españoles en la región: Nueva Barcelona del Cerro Santo, San Miguel de Nueva Tarragona y San Cristóbal de Cumanagotos. Además, Cumaná fue el nombre genérico con el que se conoció a la capital de la Provincia de la Nueva Andalucía (Carrocera, Misión XVIII).

Como capitanía general con sede en Cumaná, la Provincia de Nueva Andalucía dependía del Nuevo Reino de Granada y de la Audiencia de Santo Domingo. Los gobernadores debían visitar el territorio

Io En el mismo lugar se lee que en el siglo XVIII "se dejó de atender a Trinidad y en cambio se dio un gran impulso a la parte de Guayana, llamada también del Caroní por comprender la zona regada por este río hasta un poco más arriba de su confluencia con el Orinoco, y toda la actual Guayana venezolana”. Además, sobre la Misión de Maracaibo señala que "comprendía en total dicha misión desde las costas orientales del golfo de Maracaibo, por oriente, hasta el río Magdalena por occidente, teniendo al norte el mar Caribe y llegando por el sur a la ciudad de Ocaña. En 1749 se dividió, quedando los valencianos con la parte de Santa Marta y toda la región de la Guajira, incluso la venezolana, y encargándose los Capuchinos navarros de la parte de Maracaibo y la Grita”. Finalmente, el autor aclara que a estas misiones hay que añadir "como misión aparte, aunque en cierto modo dependió de la de los llanos, la llamada del alto Orinoco y Rionegro, de muy corta duración. Se fundó en 1756 a petición de la Comisión de Límites, pero los primeros misioneros no llegaron allí sino en 1764. Comprendía una extensa región en las fuentes del Orinoco y Rionegro y llegaba hasta las misiones de los Jesuítas [sic], por una parte, y por la otra, hasta la de los Franciscanos. Perduró solamente hasta 1773 , y, aunque se dan ig los pueblos allí fundados, propiamente los Capuchinos no fundaron sino seis" (Carrocera, Misión XVIII). 


\begin{abstract}
y enviar periódicamente informes al rey y Consejo de Indias sobre todo lo relativo al aspecto militar, económico y administrativo de la provincia y preocuparse del buen orden y marcha de las misiones. Por eso los misioneros le estaban sujetos en muchas cosas. (Carrocera, Misión XXV) ${ }^{\mathrm{n}}$
\end{abstract}

En tales circunstancias, los capuchinos hispanos pudieron dedicarse a la Misión de Cumaná aun en el siglo xix. Aburre y Longás han periodizado esta misión en cinco etapas: I) desde la fundación del primer "poblado de misión" hasta I700; 2) de 1700 a I736, cuando "la misión se extiende hasta el Guarapiche”; 3) entre 1736 y I760, al ampliar la zona de misión entre los indígenas parias y guaraúnos; 4) desde 1760 hasta 1780 , cuando los misioneros trabajaron principalmente desde el golfo Triste hasta el Orinoco y su delta; y 5 ) desde 1780 hasta el inicio de la guerra emancipadora de I8Io (Abaurre y Longás 85-87).

El padre José de Carabantes fue actor y testigo de la primera etapa. Aunque es verdad que la figura de este capuchino merece un título aparte, aquí nos contentaremos con presentar un tosco esbozo de su vida. Nació en Carabantes, un pueblo de Soria, en 1628, y fue bautizado con el nombre de José Velázquez Fresnada. Con 16 años decidió ingresar a la ofmcap, se ordenó sacerdote en I652 y tras desarrollar una intensa vocación misionera - cuya conveniencia consultó con "algunos varones doctos y almas devotas", como Francisca Carbi o la afamada María de Jesús de Agreda-, entró a formar parte, junto con otros cinco compañeros, de la empresa que dirigía el padre Lorenzo de Magallón en Cumaná (Nueva Granada). (Ureña iıo)

En I659 volvió a España por problemas de salud pero a finales de 1660 estaba nuevamente en América. En 1666 salió de nuevo rumbo a la Península por su mala salud, pero, según Urueña, la llegada de Carabantes a España escondería otros fines. Tanto él como Lorenzo de Magallón tenían un claro deseo de informar a la Congregación de Propaganda Fide del desarrollo de las empresas capuchinas, con la intención de obtener el permiso para fundar una nueva misión, la de Santa Marta. Por ese motivo, el capuchino viajó a Roma, donde entregó al colegio cardenalicio y al Santo Padre un documento en voz

II Diferente fue lo que sucedió en la Misión del Darién pues las cartas del padre Antonio de Oviedo revelan que algunos de sus compañeros de misión no le daban la autoridad de prefecto - como la tenía-, lo que desencadenó varias indisciplinas entre los religiosos que tenía bajo su comisión (Pena 1003-1046). 
de indios en el que cinco caciques reconocían al papa como vicario de Cristo, rindiéndole obediencia y fidelidad (Ureña III).

En ese viaje, Magallón y Carabantes actuaron motu proprio - sin licencias de los prelados capuchinos-, por lo que fueron castigados con la prohibición de volver a Cumaná. Así, desde i668 José de Carabantes llevó a cabo actividades misionales en Andalucía, Extremadura, Castilla, Asturias y, principalmente, en Galicia, hasta el año de su muerte, acaecida en 1694.

Lo que interesa rescatar aquí es que, en I666, estando el capuchino en Sevilla de regreso de Cumaná, recibió el encargo del marqués de Aytona de escribir una relación sobre los progresos de la misión. Rápidamente, en el mismo año circulaba en Sevilla la impresión de la relación, de la que se conocen dos ediciones. Aunque ambas conservan los datos de pie de imprenta (Copia de la carta), una de ellas cuenta con portada, letra capital y licencia, lo que hace suponer que el apetito sevillano de nuevas sobre las "Indias Occidentales" provocó tal demanda que, luego de la primera impresión, carente de licencia, se hiciera un segundo tiraje con una edición más adornada ${ }^{12}$. Además, vistas las aspiraciones de Magallón y de Carabantes de conseguir licencias para expandir el apostolado capuchino en la región de Cumaná, resulta lógico suponer que las impresiones de la carta sirvieron como propaganda para los misioneros capuchinos.

La epístola comienza con un breve recuento de lo azarosos que eran los viajes transatlánticos y de la necesidad de la improvisación ante las dificultades:

habiendo llegado a estos puertos de Andalucía seis religiosos capuchinos, que el año de 1657 salimos de la Provincia de Aragón, con orden de su Majestad, y de su Real Consejo de Indios, para pasar a las Occidentales a la conversión de los indios infieles, que habitan en la Provincia de Cumaná; viendo que los galeones no salían con la brevedad que deseábamos, dispuso el prefecto y superior de esta misión que en una nao, que hacía viaje para las costas de dicha provincia, fuesen delante de los demás tres de dichos religiosos, que el capitán de dicha nao

12 Aunque el contenido sustancial de la carta en ambas impresiones no varía, los títulos sí. La que suponemos fue la primera impresión se titula Copia de la carta, que el V. P. Fray Joseph de Carabantes Missionario Apostólico Capuchino, escriviò desde Sevilla al Excelentissimo señor Marquès de Aytona, recien llegado de Indias [...]. En la edición con portada, letra capital y licencia se lee Copia de Carta escrita a el Excelentissimo señor Marques de Aytona, \&c. por el P. Fr. Ioseph de Caravantes, religioso capuchino missionario por su Magestad en sus Indias Occidentales, entre el Barbarismo ciego de diversas Naciones de Infieles, que habitan en las Provincias de Caracas y Cumaná [...]. En adelante, extraigo las citas del primer documento, modernizando su transcripción. 
quiso llevar de limosna. Y habiendo hecho el viaje, y llegado a dichas costas de Indias, y reconocido que por entonces (por varias causas) no era posible entrar en las tierras de los indios infieles, en el ínterin que llegaban a incorporarse los otros tres religiosos que quedaban acá para pasar después en los galeones, les pareció hacer misiones, predicando y confesando en las ciudades de aquellas costas, que se componen de españoles, de negros, indios y mulatos. (Copia de la carta I)

En efecto, los misioneros que viajaron de limosna hacia América llegaron a la ciudad de Trujillo, donde encontraron que las religiosas del convento "apenas tenían conocimiento de lo que era oración mental”. Los frailes de la vanguardia enseñaron a las monjas "a tener cada día una hora de dicha oración mental de comunidad”, teniendo tanto éxito que aquellas, escribe Carabantes, decidieron instituir en su cenobio no una, sino dos horas diarias dedicadas a este ejercicio. Además, predicaron y reformaron las costumbres y los trajes en Caracas, Nueva Valencia, Nueva Segovia, "Nilgua" [sic: Nirgua], Tocuyo, Carora, Maracaibo, la Margarita, Cumaná, Nueva Barcelona, "Cumanagoto", "Cumanacoa” y en otra decena de ciudades, lo que podría suponer que la espera del segundo contingente se prolongó durante algunos meses (Copia de la carta 3).

Entrados ya en la zona de misión, Carabantes refiere que era patente que los nativos estaban dispuestos a matar europeos, "y aun los indios caribes para asarlos y comerlos", pero gracias a la asistencia divina "no se atrevieron a ejecutar sus intentos". En tales expediciones los capuchinos necesitaron fortaleza física y mental pues "se encontraban a cada paso pantanos y tales, que se metían en ellos los religiosos (sin saber cómo) hasta cerca de la cintura, y a veces era menester mucho tiempo y ayuda para salir de ellos", además de que debían conformarse con comer en todo el día "un poco de pan de raíz de árbol, tan áspero, que al pasarlo parece iba aserrando la garganta" (Copia de la carta 4).

Sobre el problema de la reducción de indios, parece que en Cumaná tal tarea solo podía intentarse con los "bárbaros [que] nos recibían medio bien", aunque incluso estos se negaban a dejar "sus casas y los huesos de sus padres, abuelos y parientes que en ellos [sic: ellas] tenían enterrados". Incluso, refiere la existencia de un español que, inspirado por el demonio, convenció a ciertos naturales "que ya estaban movidos para su conversión" de que "no nos permitieran sus tierras", pues les hizo creer que la finalidad de los misioneros era hacerlos esclavos. Por estas razones, "todo fue padecer a secas y trabajar sin fruto entre estos bárbaros, por espacio de dos años y medio" (Copia de la carta 3). 
De ahí que desde 1659 los capuchinos cambiaran de estrategia: en lugar de dirigirse al pueblo llano, comenzaron a adoctrinar a los caciques de los "bárbaros" cumanagotos, logrando así que "el gentío a ellos sujeto" aceptara reducirse en un "ameno prado [...] que llaman Cerro de Guacharo", para fundar la primera población y su iglesia con el nombre de Santa María de los Ángeles. Siguiendo el mismo programa, entre i66o y i664, "se tomaron cinco fundaciones más y se formaron otros tantos pueblos e iglesias, fabricando estas los religiosos por sus propias manos, cortando antes las maderas necesarias y cargando sobre sus hombros los materiales" (Copia de la carta 6). Así se fundaron las poblaciones de Nuestra Señora del Pilar, San Salvador, San Juan Bautista y San Francisco, ubicadas en la provincia de Cumaná; y San Antonio de Padua y Pao, en la provincia de Caracas.

Carabantes informa que las "conveniencias temporales" de la Misión de Cumaná para la monarquía española eran "no pocas, ni pequeñas", considerando que los capuchinos habían logrado que "bárbaros belicosos" entablaran "paz y amistad con los españoles [...], rindiéndose también a la obediencia y vasallaje del rey católico". Con esta nueva situación, los espańoles podían entrar en las tierras de los nativos para "sacar el ganado vacuno que quisieren y recoger sebo y corambre", y vivir seguros "en sus valles con las haciendas de campo y ganado vacuno y caballar; siendo así que antes no las podían cultivar, ni mantener por las invasiones que cada día les hacían los caribes" a españoles, negros, mulatos "y demás gente de su servicio" (Copia de la carta 7-8).

Carabantes retrató a los caribes como el paradigma de la idílica armonía entre los naturales y la Corona. Según sus letras, antes del establecimiento de las misiones capuchinas estos indígenas "no dejaban vivir en aquellas costas a los españoles, persiguiéndolos por mar y por tierra, degollando los que podían coger, asándolos y comiendo sus carnes”. Sin embargo, hacia I666, los caribes ya hacían una ceremonia para celebrar "el acto de obediencia y pases en presencia de los ministros reales y de nuestros religiosos", consistente en

hacer pedazos un arco y flechas, que son las armas ordinarias de aquellos bárbaros y, haciendo un hoyo en la tierra, las entierran en él diciendo: Ya queda la guerra sepultada para con los españoles y la paz queda sobre la tierra". (Copia de la carta 7. Énfasis con cursiva añadido)

Las favorables condiciones que la presencia capuchina había generado en Cumaná entre I657 y 1666 posibilitaban mayores glorias a España porque "está fácil y llano el camino para el descubrimiento del gran tesoro de El Dorado que 
(según tradiciones de los naturales de aquella tierra) está no mucho más delante de las provincias de nuestra misión" (Copia de la carta 7, 9). Si bien el capuchino reconocía que la "tradición de este tesoro" no era cierta, aunque corría la leyenda por Caracas y Cumaná, la enunciación de El Dorado le sirvió para afirmar que en Cumaná había "muchas señales de riquísimos minerales de oro, de que no hacen aprecio los naturales indios" (Copia de la carta 1o).

Para corroborar el éxito de la empresa evangelizadora, José de Carabantes describió brevemente algunos casos particulares de conversiones y las conversiones milagrosas, en las cuales era el demonio el enemigo al que se debía vencer. No obstante, la efectividad de la empresa se certificaba con el afecto que los caribes de las islas de Barlovento les mostraban, pues, aun cuando estaban "habituados a sustentarse de carne humana", solicitaron la doctrina de los capuchinos en sus lugares $y$

para que nos asegurásemos de que no nos quitarían la vida, ni molestarían nuestras personas, ofrecieron dejar en rehenes algunos de sus hijos, en poder del gobernador de Cumaná, para que en ellos se pudiese vengar cualquier agravio que se nos hiciese. (Copia de la carta II-I4)

Finalmente, para darle mayor lustre al trabajo realizado en la Misión de Cumaná, Carabantes cerró su carta refiriendo algunos milagros que, por mediación divina, habían podido obrar los capuchinos entre los "infieles" de la zona. De un religioso escribió que al predicar "iban saliendo de su boca unas como estrellas"; de otro, manifestó que había curado a un muchacho mudo; y de uno más apuntó que "llegando a una casa, en ocasión que los de ella estaban llorando a una muchacha (que decían se les había muerto), la tomó de la mano diciendo las palabras que Cristo vida nuestra dijo en semejante ocasión: No está muerta la muchacha, sino que duerme, se levantó viva y sana" (Copia de la carta I8-I9. Énfasis con cursiva en el original).

\section{Colofón}

La entrada de los capuchinos hispanos a América revela que las tensiones entre la Congregación de Propaganda Fide y el Consejo de Indias —influidas por el histórico rechazo de Carlos V y de Felipe II a la orden, a la que concebían como "secta"- permanecían aún en tiempos de Felipe IV, a pesar del apoyo que el mismo monarca prestó a la congregación. Además, evidencia la franca guerra 
entre ingleses, holandeses, portugueses, franceses, italianos y españoles por las zonas de misión, convirtiéndose estos también en sujetos de predicación, por lo que tuvieron que misionar en zona de "infieles", entre "herejes" y en medio de pugnas con otras órdenes religiosas. Más aún, considerando la decadente condición económica de España y, paradójicamente, la fuerza de la maquinaria diplomática y clientelar en tiempos de Felipe IV que descubren los asuntos aquí explicados, no parece claro quién tenía el poder de facto y el poder simbólico en estas regiones de América: ¿la Iglesia o la monarquía?, ¿el papa o el rey? Finalmente, los escritos de Oviedo y Carabantes expuestos aquí indican que no existió una única forma de evangelización, sino que aun a mediados del siglo XVII, los religiosos inventaban formas para sobrevivir y comunicar la palabra de su Dios.

Cabe cuestionarse sobre la noción de América que, durante la primera mitad de siglo XVII, los misioneros capuchinos exportaron a Europa desde remotos lugares mediante ese artefacto llamado carta, porque de la triste realidad del siglo Xvir emergía la conciencia colectiva del fracaso en las Indias, como lo revelan las cartas de fray Antonio de Oviedo. Fracaso militar, pero también - y sobre todo- fracaso del reconocimiento de la otredad. En esa península metafísica, en la que se consumían masivamente historias sobre los tesoros contenidos en El Dorado y el canibalismo de los caribes, en ese lugar en el que a los "indios" había que "enseñarles a ser hombres antes que cristianos", poco se publicitaba la violencia real que se vivía en el continente americano aun a mediados del siglo XVII.

\section{8 \\ B I B L I O G R A F í A}

\section{I F U E N T ES PR I M A R I S}

\section{A. Impresos}

Boverio, Zacarías. Tercera parte de las Chronicas de los Frailes Menores Capuchinos de N. P. S. Francisco, traducción de Francisco Antonio de Madrid Moncada. Madrid: Carlos Sánchez, 1647 . 
Copia de la carta, que el V. P. Fray Joseph de Carabantes Misionario Apostólico Capuchino, escribió desde Sevilla al Excelentisimo señor Marqués de Aytona, en que le da noticia ... de los trabajos, sucesos, y progresos de su viaje, y primera Misión de India. Sevilla: imprenta de Juan Gómez de Blas, 1666.

Pise, Marcelino de. Quarta parte de las Chronicas de los Frayles Menores Capuchinos de N. S. P. S. Francisco, traducción de José de Madrid. Madrid: Bernardo de Villadiego, 1690.

\section{I F U E N TES SECUNDARIA S}

Abaurre Valencia, Miren Maite y Luis Longás Otín. “Aportación al estudio de las misiones en América: los capuchinos aragoneses y la misión de Cumaná (I650-I8Io)”. Argensola: Revista de Ciencias Sociales del Instituto de Estudios Altoaragoneses, n. ${ }^{\circ}$ Io I, I988, pp. 77-96.

Carrocera, Buenaventura de. "Los capuchinos españoles en el Congo y el primer diccionario congolés”. Missionalia Hispanica, n. ${ }^{\circ}$ 5, 1945, pp. 209-230.

--.. "El Consejo de Indias y las misiones de los capuchinos españoles”. Miscellanea Melchor de Pobladura. Vol. II, editado por Melchor de Pobladura e Isidoro Agudo. Roma: Institutum historicum, 1964, pp. 279-311.

-.-. Lingüistica indigena venezolana y los misioneros capuchinos. Caracas: Universidad Católica Andrés Bello, 1981.

---. Misión de los Capuchinos en Cumaná. Tomo I. Caracas: Academia Nacional de la Historia, 1968.

---. La Provincia de Frailes Menores Capuchinos de Castilla. Vol. I. Madrid: Administración de El Mensajero Seráfico, i949.

Echeverría, José Ángel. “Conventos capuchinos existentes en España al tiempo de la exclaustración (1835)”. Naturaleza y Gracia: Revista Cuatrimestral de Ciencias Eclesiásticas, n. ${ }^{\circ}$ 2-3, 2004, pp. 1057-1069.

Helms, Mary W. "Los indios del Caribe y del Circuncaribe a finales del siglo Xv". Historia de América Latina. Vol. I, editado por Leslie Bethell. Barcelona: Crítica, I990, pp. 31-48.

Hernández Sotelo, Anel. Una historia de barbas y capuchas. La deconstrucción de la figura de san Francisco por los frailes capuchinos. Siglos XVII-XVIII. Bogotá: ICANH, 2017.

Pacheco, Juan Manuel. Losjesuitas en Colombia. Tomo III. Bogotá: Universidad Javeriana, 1989.

Pena González, Miguel-Anxo. "Fr. Antonio de Oviedo: prefecto de la Misión del Darién”. Naturaleza y Gracia: Revista Cuatrimestral de Ciencias Eclesiásticas, n. ${ }^{\circ}$ 2-3, 2004, pp. 1003-1046. 
Pobladura, Melchor de. "Génesis del movimiento misional en las provincias capuchinas de España (I618-1650)”. Estudios Franciscanos, n. ${ }^{\circ}$ 50, 1949, pp. 209-280 y 353-385.

Smutko, Gregorio. "Los capuchinos en Panamá en el siglo XVII". Naturaleza y Gracia: Revista Cuatrimestral de Ciencias Eclesiásticas, n. ${ }^{\circ}$ I, I990, pp. I07-II3.

Ureña Palomo, Ángel Gabriel. “'Los papeles, sermones y demás alhajas de la misión’. José de Carabantes y la escritura misionera en la España del siglo XviI”. Tiempos Modernos, vol. 8, n. $^{\circ} 34,2017$, pp. $108-134$. 